\title{
Profil Hamba Tuhan Sejati dan Hubungannya Dengan Efektivitas Para Pelayan Tuhan di GSJPDI ‘Adityawarman' Surabaya
}

\author{
Widi Prasetyo $^{1)}$, Daniel Ari Wibowo' ${ }^{2)}$ \\ 1) Evangelical Theological Seminary of Indonesia - Surabaya \\ E-mail:widiprasetyo@sttii-surabaya.ac.id \\ 2) Evangelical Theological Seminary of Indonesia - Surabaya \\ E-mail: ariwibowodaniel@sttii-surabaya.ac.id
}

\begin{abstract}
The organization is a complex unit that seeks to allocate resources fully for the achievement of objectives. Both the resources relating to facilities and infrastructure as well as human resources. If an organization is able to achieve its stated goals, it can be said that the organization is effective. One of the goals of the organization is to achieve employee effectiveness and efficiency. Every organization needs to pay attention to the issue of work effectiveness where work effectiveness is the ability of employees to carry out work to bring the results that have been determined previously. For the Director, effectiveness is the key to organizational success. Effectiveness is not just doing the job right but how to focus resources and efforts for it. Efficiency is the use of minimum resources to achieve optimum results. Efficiency assumes that the correct goals have been determined and tries to find the best ways to achieve these goals. Efficiency can only be evaluated by relative judgments, comparing input and output received. An organization, both government and private organizations formed to achieve goals, needs factors that can be in the form of human resources, materials and tools to support activities. Of these three factors, human factors are the most dominant factors. In the effort to achieve organizational goals, humans are very important factors. Because humans are the main actors of the organization, it needs special attention compared to others. As the most important factor, people with the ability to carry out their duties will influence the success or failure of the organization in achieving its objectives.
\end{abstract}

Keywords: organization, effective, servant Of God, objectives

\begin{abstract}
Abstrak
Setiap organisasi perlu memperhatikan masalah efektivitas kerja di mana efektifitas kerja merupakan kemampuan dari para karyawan dalam melaksanakan pekerjaan untuk mendatangkan hasil yang telah ditetapkan sebelumnya. Bagi Direktur, efektifitas adalah kunci keberhasilan organisasi. Efektifitas tidak hanya melakukan pekerjaan dengan benar tetapi bagaimana melakukan memusatkan sumber daya dan upaya untuk itu.Efisiensi adalah penggunaan sumber daya secara minimum guna pencapaian hasil yang optimum. Efisiensi menganggap bahwa tujuan-tujuan yang benar telah ditentukan dan berusaha untuk mencari cara-cara yang paling baik untuk mencapai tujuan-tujuan tersebut. Efisiensi hanya dapat dievaluasi dengan penilaian-penilaian relatif, membandingkan antara masukan dan keluaran yang diterima. Suatu organisasi baik organisasi pemerintah maupun swasta yang
\end{abstract}


dibentukuntuk mencapai tujuan, perlu faktor-faktor yang dapat berupa sumber daya manusia, material dan alat-alat penunjang kegiatan. Dari ketiga faktor tersebut, faktor manusia merupakanfaktor yang paling dominan.Dalam usaha mencapai tujuan organisasi, manusia merupakan faktoryang sangat penting. Karena manusia menjadi pelaku utama organisasi maka perlumendapat perhatian khusus dibanding yang lainnya. Sebagai faktor yangpaling penting, manusia dengan kemampuan yang dimiliki dalam menjalankantugasnya akan mempengaruhi berhasil tidaknya organisasi dalam mencapai tujuan.

Kata Kunci: organisasi, efektivitas, Hamba Tuhan, mencapai tujuan

\section{PENDAHULUAN}

Hamba Tuhan adalah salah satu pribadi yang dipanggil dan ditetapkan oleh Tuhan untuk menjadi pelayanNya. Dan sebagai hamba, ia mendapat tugas dari Tuhan untuk menyampaikan kebenaran dan melaksanakan amanat agung.

Seorang Hamba Tuhan tidak hanya menyampaikan kabar baik atau injil tetapi juga kehidupan hamba Tuhan itu sendiri adalah kabar baik. Artinya bahwa kehidupan yang di miliki memberikan suatu kabar baik atau keteladanan dalam menyampaikan dan menjadi kabar baik. Sehingga menjadi pemimpin yang melayani, menjadi teladan bagi semua orang, yaitu dalam perkataan, tingkah laku,kasih,kesetiaan, dan kesucian hidup, seperti yang dituliskan dalam 1 Timotius 4:12. Pelayanan seorang hamba bukan dititikberatkan pada pekerjaan, metode, pendidikan, pengalaman dan lain - lainnya, melainkan pada hidup rohaninya dan karakternya. Pdt. Philip Teng mengatakan dalam buku "Problematika Hamba Tuhan":Pelayanan seorang hamba Tuhan yang sungguh adalah pelayanan yang disertai dengan hidup, khotbah yang disertai dengan hidup, bekerja disertai dengan hidup.

Pelayanan yang disertai dengan hidup demikian adalah dasar pelayanan seorang

\footnotetext{
${ }^{1}$ Yap Un Han. Problematika Hamba Tuhan ( Manado: Yayasan Daun Family, 2004), 36
}

hamba Tuhan. ${ }^{1}$ John Stott, orang yang di pakai Tuhan sebagai seorang tokoh gereja di Inggris, dalam bukunya mengatakan bahwa seorang hamba atau pelayan Allah bukan seorang nabi, rasul, atau orang yang sembarangan bicara, melainkan seorang jurukunci. Artinya adalah seorang yang pilih dari semua orang yang ada dengan status tetap sebagai hamba untuk bertanggung jawab mengatur rumah-tangga tuannya $^{2}$

Dari abad ke abad makna panggilan seorang Hamba Tuhan sebagian besar sudah salah, dimana penggunan arti "seorang hamba" pada pribadi seorang hamba Tuhan sudah hilang. Hal itu terbukti dalam Alkitab Markus 10:35:45,yaitu murid Tuhan Yesus (Yohanes dan Yakobus) yang meminta suatu kedudukan kepada Yesus. Para murid lebih mementingkan sebuah kedudukan daripada untuk melayani.

Orang lebih memikirkan kedudukan, status atau gelar atau lebih mencari kehormatan dari pada melayani dengan kerendahan hati.

Tuhan memanggil hamba-Nya bukan untuk menjadi bos,melainkan menjadi hamba. Tuhan bukan menitik beratkan gaya. kepemimpinan, kewibawaan, melainkan sikap sebagai seorang hamba

${ }^{2}$ Ibid 
yang melayani orang lain. ${ }^{3}$ Melihat fenomena yang terjadi di dalam kehidupan para hamba Tuhan sekarang ini maka penulis mengangkat judul tentang Profil Hamba Tuhan yang Sejati yang sesuai dengan kebenaran Firman Allah. Dan akan melakukan Penelitian tentang hubungan profil hamba Tuhan yang sejati dengan efektifitas pelayan - pelayan Tuhan di Gereja Sidang Jemaat Pentakosta Di Indonesia (GSJPDI) Adityawarman, Jl.Adityawarman 44 Surabaya.

Penelitian sangat diperlukan untuk mendapatkan dan menghasilkan pelayan pelayan Tuhan yang memiliki hidup dan pelayanan yang sesuai dengan kehendak Tuhan. Sehingga hidup dan pelayanan seorang pelayan Tuhan dapat memberikan sumbangsih bagi pertumbuhan iman umat Tuhan, bukan hanya bagi dirinya sendiri.

Kehidupan dan pelayanan hamba Tuhan sangat memberi manfaat bagi gereja - gereja guna pertumbuhan iman kepada Kristus. Akan tetapi banyak pelayanan hamba - hamba Tuhan yang melayani supaya orang lain menyukainya, di kagumi oleh banyak orang, dan supaya mencapai tujuan - tujuannya sendiri. Dan hal ini merupakan manipulasi dan bukan pelayanan. ${ }^{4}$

Pemahaman Kitab Lukas 17:7-10, adalah menggambarkan profil hamba Tuhan yang sejati yang bisa jadi pedoman bagi hamba - hamba Tuhan dan pelayan pelayan pada masa kini khususnya di gereja GSJPDI Adityawarman.Pelayan-pelayan Tuhan di GSJPDI Adityawarman adalah merupakan perpanjangan tangan Allah untuk menjadi berkat,menguatkan,

\footnotetext{
${ }^{3}$ Yan Un Han, Problematika Hamba Tuhan (
} Manado:Yayasan Daud Family, 2004),36 menyatakan kebenaran, dan juga menjadi teladan bagi jemaat GSJPDI Adityawarman.

\section{METODE PENELITIAN}

Dalam penelitian ini peneliti menggunakan tipe penelitian kuantitatif jenis penelitian survei. Dalam Jenis penelitian survei data dikumpulkan dan hubungan (korelasi) antara berbagai perubah diselidiki untuk memberi gambaran terhadap objek penelitian. Tehnik-tehnik survei dipelajari dalam metode survei. Penelitian tipe survei paling sering di bidang ilmu sosial yang berkaitan dengan perilaku sehari-hari.

Penelitian survei adalah penelitian yang dilakukan pada populasi besar maupun kecil, tetapi data yang dipelajari adalah data dari sample yang diambil dari populasi tersebut, sehingga ditemukan kejadian-kejadian relatif, distribusi, dan hubungan-hubungan antar variable. Contoh: penelitian untuk mengungkapkan kecenderungan masyarakat dalam memilih pemimpin nasional dan daerah, kualitas SDM masyarakat Indonesia. ${ }^{5}$ Dalam penelitian survei ini menggunakan bentuk kuisioner yang berhubungan juga dengan populasi dan sampel. Dengan kata lain bahwa survei adalah metode pengumpulan data dengan menggunakan instrumen untuk meminta tanggapan dari responden tentang sampel yang mewakili populasi dan hal itu didapatkan langsung dari responden tersebut. Menurut Richard West dalam bukunya yang berjudul Pengantar Teori Komunikasi mengatakan bahwa: Penelitian survei (survei Recearch) adalah bentuk

\footnotetext{
${ }^{4}$ Rick Warren. The Purpose Driven Life (Malang: Gandum Mas,2001)

${ }^{5}$ http://merahitam.com/metode-penelitian-jenisdan-data.html
} 
pengumpulan data yang menggunakan kuisioner yang disebarkan kepada kelompok orang,dan respon yang di berikan memungkinkan peneliti untuk menarik kesimpulan mengenai keseluruhan kategori orang- orang yang diwakili oleh responden. 6

\section{HASIL DAN PEMBAHASAN}

Dari penelitian yang telah di lakukan maka peneliti mendapatkan deksripsi data tentang responden yang dapat di lihat sebagai berikut

Tabel 1.1

Nilai Frekuensi berdasarkan jenis kelamin

\begin{tabular}{|c|c|c|}
\hline Jenis kelamin & Frekuensi & Persentase \\
\hline laki - laki & 17 orang & $47,7 \%$ \\
\hline Perempuan & 21 orang & $55,3 \%$ \\
\hline Total Jumlah & 38 orang & $100 \%$ \\
\hline
\end{tabular}

Keterangan di atas menjelaskan tentang nilai frekuensi sampel sebanyak 38 orang pelayan Tuhan dengan keterangan jenis kelamin laki - laki ada 17 orang dengan presentase $47,7 \%$ dan jenis kelamin perempuan ada 21 orang dengan persentase $55,3 \%$.

Tabel 1.2

Nilai Frekuensi berdasarkan Umur

\begin{tabular}{|c|c|c|}
\hline Umur & Frekuensi & Persentase \\
\hline$\leq 20$ Thn & 6 orang & $15,7 \%$ \\
\hline $21-30$ Thn & 12 orang & $31,5 \%$ \\
\hline $31-40$ Thn & 5 orang & $13,1 \%$ \\
\hline $41-50$ Thn & 9 orang & $23,6 \%$ \\
\hline
\end{tabular}

\footnotetext{
${ }^{6}$ Richard West. pengantar teori Komunikasi (Jakarta: Salemba Humanika, 2008 ), 79.
}

51-60 Thn

6 orang

$15,7 \%$

Berdasarkan umur Pelayan Tuhan di Gereja Sidang Jemaat Pentakosta yaitu $\leq 20$ Tahun ada 6 orang pelayan Tuhan dengan persentase 15, $7 \%$, umur 21- 30 Tahun ada 12 orang pelayan Tuhan dengan persentase $31,5 \%$, umur 31 - 40 Tahun ada 5 orang pelayan Tuhan dengan persentase $13,1 \%$, umur 41 - 50 Tahun ada 9 orang Pelayan Tuhan dengan persentase $23,7 \%$, dan umur 51- 60 Tahun ada 6 orang pelayan Tuhan dengan persentase $15,7 \%$. Sehingga dapat di simpulkan bahwa sebagian besar pelayan Tuhan yang melayani memiliki umur 2130 tahun.

Tabel 1.3

Nilai Frekuensi berdasarkan pendidikan

\begin{tabular}{|c|c|c|}
\hline Pendidikan & Frekuensi & Persentase \\
\hline SMP & 1 Orang & $2,63 \%$ \\
\hline SMA & 26 Orang & $68,4 \%$ \\
\hline S1 & 11 Orang & $28,9 \%$ \\
\hline
\end{tabular}

Di lihat dari tingkat pendidikan maka jumlah pelayan Tuhan di Gereja Sidang Jemaat Pentakosta di Indonesia yang berpendidikan SMP ada 1 orang dengan persentase 2, $63 \%$, jumlah pelayan Tuhan yang berpendidikan SMA ada 26 orang dengan persentase $68,4 \%$, jumlah pelayan Tuhan yang berpendidikan S1 ada 11 orang dengan persentase $28,9 \%$. Sehingga dapat di simpulkan bahwa pelayan Tuhan sebagian besar memiliki tingkat pendidikan SMA. 
Tabel 1.4

Nilai Frekuensi berdasarkan Lama Melayani

\begin{tabular}{|c|c|c|}
\hline $\begin{array}{c}\text { Lama } \\
\text { Melayani } \\
\leq 5\end{array}$ & Frekuensi & Persentase \\
\hline $5-10 \mathrm{THN}$ & 14 Orang & $23,6 \%$ \\
\hline $11-15 \mathrm{THN}$ & 4 Orang & $10,5 \%$ \\
\hline $16-20 \mathrm{THN}$ & 5 Orang & $13,1 \%$ \\
\hline $21-25 \mathrm{THN}$ & 1 Orang & $0,38 \%$ \\
\hline$\geq 26 \mathrm{THN}$ & 5 Orang & $13,1 \%$ \\
\hline
\end{tabular}

Berdasarkan lama melayani maka pelayan Tuhan dengan lama melayani $\leq 5$ ada 9 orang dengan persentase $23,6 \%, 5-$ 10 tahun melayani ada $36,8 \%, 11-15$ tahun ada $10,5 \%, 16-20$ tahun ada 13,1 $\%, 21-25$ Tahun ada $0,38 \%, \geq 26$ tahun ada $13,1 \%$. Jadi rata - rata pelayan Tuhan telah melayani di Gereja Sidang Jemaat pentakosta dengan lama melayani paling banyak antara 5-10 Tahun dalam pelayanan.

\section{Analisis Data}

Di dalam kamus Webster's New Dictionary, salah satu arti dari analisis(analysis) adalah " anlysis, it means separating or breaking up of any whole into its parts so as to find out their nature, proportion, function, relationship, etc." Jadi pada dasarnya membuat analisis berarti menguraikan lebih lanjut, misalnya dari suatu total menjadi subtotal agar bisa dibandingkan antara

subtotal yang satu dengan subtotal lainnya atau memperkirakan besarnya pengaruh perubahan satu atau beberapa variabel terhadap variabel lainnya secara kuantitatif, didalam rangka mencari variabel yang mungkin menyebabkan suatu kejadian atau berubahnya nilai suatu variabel. $^{7}$

Tabel 2.1

Scale Statistics

\begin{tabular}{|c|r|r|r|}
\hline Mean & Variance & $\begin{array}{c}\text { Std. } \\
\text { Deviation }\end{array}$ & N of Items \\
\hline 177.05 & 180.484 & 13.434 & 41 \\
\hline
\end{tabular}

Tabel $\mathrm{n}=50$ adalah 0,279 dan $\mathrm{c}$ a $>0.7$ Regresi-corelasi

Tabel 2.2

Descriptive Statistics

\begin{tabular}{|l|r|r|rr|}
\hline & \multicolumn{1}{|c|}{ Mean } & Std. Deviation & \multicolumn{1}{|c|}{ N } \\
\hline SUMY & 72.32 & 6.081 & & 38 \\
SUMX & 104.74 & 8.242 & & 38 \\
\hline
\end{tabular}

Pada bagian tabel di atas menjelaskan gambaran tentang dua variabel yang diregresikan, yakni efektifitas pelayan Tuhan ( Y) dengan Profil hamba Tuhan Sejati ( $\mathrm{X})$. Dengan isi gambarannya adalah mean ( rata - rata ) $Y=72,32$ dan $X$ $=104,74$ dengan standar deviasi ( simpangan baku ) $\mathrm{Y}=6.081$, dan $\mathrm{X}=8.282$, dan $\mathrm{N}($ jumlah subjek $)=38$.

Tabel 2.3

\begin{tabular}{|c|l|r|r|}
\hline \multicolumn{4}{|c|}{ Tabel 2.3} \\
Case Processing Summary \\
\hline \multirow{4}{*}{ Cases } & Valid & 38 & 100.0 \\
\cline { 2 - 4 } & Excluded $^{\mathrm{a}}$ & 0 & .0 \\
\cline { 2 - 4 } & Total $^{*}$ & 38 & 100.0 \\
\hline
\end{tabular}

Dari tabel di atas diterangkan bahwa jumlah responden atau sampel dari populasi

${ }^{7}$ J.Suprapto. Statistik untuk Pemimpin berwawasan Global ( Jakarta: Salemba Empat, 2007 ), 127. 
ada 38 orang dinyatakan valid $100 \%$ atau di terima. Dimana jumlah laki-laki ada 17 orang dan perempuan ada 20 orang.

Tabel 2.4

Reliability Statistics

\begin{tabular}{|r|r|}
\hline $\begin{array}{c}\text { Cronbach's } \\
\text { Alpha }\end{array}$ & \multicolumn{2}{|c|}{ N of Items } \\
\hline 920 & 50 \\
\hline
\end{tabular}

Menurut Sugiyono menjelaskan bahwasyarat validitas dan reliabilitas adalah syarat yang menunjukkan suatu tes dinyatakan valid yakni tes tersebut mengukur apa yang hendak di ukur sesuai dengan kriteria dan dinyatakan reliabel apabila tes tersebut menunjukkan hasil yang dapat dipercaya dan tidak bertentangan. ${ }^{8}$

Syarat validitas dan reliabilitas statistiknya adalah denganCronbach's Alpha> 0,7( sekaran 2003). Jadi berdasarkan tabel di atas maka Cronbach's Alpha 0.920 jadi terlihat bahwa $0.920>0,7$. Dan dari keterangan di atas juga dimana $\mathrm{N}$ adalah jumlah pertanyaan dan ada 50 pertanyaan sebagaimana dijelaskan oleh tabel di bawah dengan nilai tabel ( corrected item total correlation) harus $>0,279$.

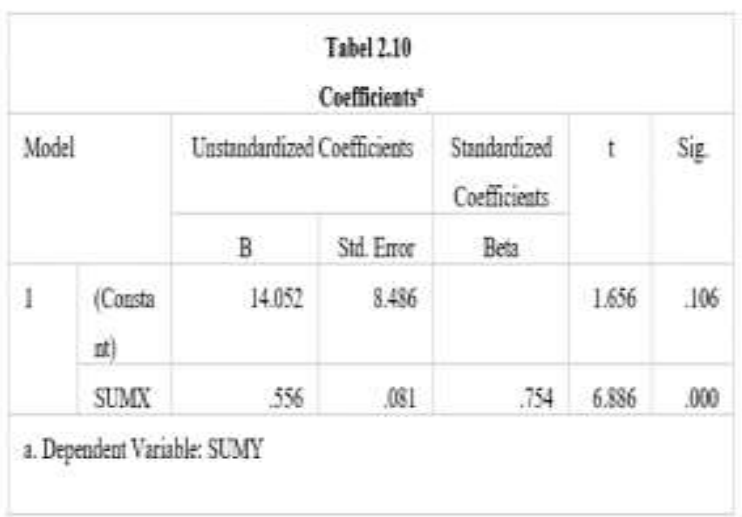

\footnotetext{
${ }^{8}$ Prof.Dr. Sugiyono. Metode Penelitian

Administrasi (Bandung: Alfabeta, 2007 ), 137.
}

Tabel di atas dikemukakan nilai koefisien a dan $b$ serta harga $t$ hitung dan juga tingkat signifikan. Dari tabel di atas di dapat $\mathrm{t}$ persamaan perhitungan sebagai berikut $: Y=14,052+0,556$

Di mana : $\mathrm{Y}=$ Efektifitas Pelayan Tuhan dan $X=$ Profil Hamba Tuhan Jadi, Nilai 14,052 merupakan nilai konstanta (a) yang menunjukkan bahwa jika tidak ada kenaikan Profil Hamba Tuhan ( X ), maka Efektifitas Pelayan Tuhan (Y) akan mencapai 14, 052.

Sedangkan harga 0,556 X merupakan koefisien regresi yang menunjukkan bahwa setiap ada penambahan 1 nilai atau angka untuk profil hamba Tuhan ( $X$ ), maka akan ada kenaikan Efektifitas pelayan Tuhan (Y) 0,556. Dan angka 0,754 pada Standardized Coefficients ( Beta ) menunjukkan tingkat korelasi antara Profil hamba Tuhan sejati dengan Efektifitas Pelayan Tuhan.

Sedangkan $\mathrm{t}$ merupakan nilai yang berguna untuk pengujian, apakah pengaruh Profil hamba Tuhan terhadap efektifitas pelayan Tuhan benar-benar signifikan atau tidak. Sehingga dapat di tarik kesimpulan dari penjelasan di atas bahwa: $\mathrm{t}=6,886$ dan $\operatorname{sig}(\mathrm{p})=0,000$, di mana $\mathrm{p}=0,000<0,05$ maka $\mathrm{Ho}_{\mathrm{o}}$ : di tolak, dan $\mathrm{H}_{1}$ : di terima. Jadi, Variabel $\mathrm{X}$ mempengaruhi Variabel $\mathrm{Y}$ dengan kategori kuat atau dengan kata lain bahwa terdapat pengaruh yang signifikan dari profil hamba Tuhan terhadap efektifitas pelayan Tuhan. Dan R Square = 0,568 artinya hubungan Profil hamba Tuhan sejati terhadap Efektifitas pelayan Tuhan sebesar 56,8\% sedangkansisanya $43,2 \%$ di pengaruhi oleh faktor lain.

\section{KESIMPULAN}

Setelah penulis membahas dan memaparkan materi tentang profil hambaTuhan sejati menurut Lukas 17:7-10, penulis dapat menyimpulkan bahwa 
keberadaan dan kesejatian hamba Tuhan bukan dinilai dari postur tubuh, profesi atau posisi tetapi dinilai keyakinan akan panggilan Tuhan atas dirinya. Selain itu kesejatian hamba Tuhan sangat berhubungan dengan karakter atau sifat. Tiga karakter dasar yang harus dimiliki oleh hamba Tuhan sejati menurut Lukas 17:7-10 yaitu: taat, tulus dan rendah hati. Tiga karakter ini sangat melekat pada keberadaan hamba Tuhan Sejati. Bahkan tiga karakter ini dapat menjadi kriteria maupun ukuran penilaian dari kesejatian seorang hamba Tuhan. Jadi jika seorang hamba Tuhan tidak memiliki tiga kriteria tersebut atau kehilangan satu saja dari tiga karakter dasar itu, maka hamba Tuhan tersebut tidak dapat disebut hamba Tuhan sejati.

Hal lain yang tidak kalah pentingnya adalah usaha merealisasikan dan mengaplikasikan tiga karakter hamba Tuhan sejati itu dalam perbuatan atau pola hidup. Dalam status sebagai pelayan Tuhan berarti berusaha mengaplikasikan dalam aktifitas pelayanan.

Melalui proses penelitian yang penulis lakukan bagi pelayan Tuhan di Gereja Sidang Jemaat Pantekosta di Indonesia Adityawarman. Penulis mendapatkan suatu pemahaman bahwa penguasaan konsep tentang keberadaan hamba Tuhan sejati sangat mempengaruhi atau sangat berdampak bagi kinerja atau efektifitas pelayanan seorang pelayan atau hamba Tuhan. Seorang pelayan atau hamba Tuhan yangmengerti dan menghayati secara benar tiga karakter hamba Tuhan Sejati dan belajar menerapkan dalam hidup dan pelalayanannya, maka akan terjadi peningkatan mutu dan efektifitas pelayanan (pelayanan yang tepat guna).

\section{DAFTAR PUSTAKA}

[1] Aritonang, Irianton. Aplikasi Satistika. Yogyakarta: Media Presindo,2005

[2] Asali,Budi.Eksposisi Injil Lukas. Golgolthaministry.com

[3] Bible Knowledge Commentary (Hak Cipta Perjanjian Lama), (C) 1.9832 .000

Masak Komunikasi Departemen;. Bible Knowledge Commentary / Hak Cipta

Perjanjian Baru (C) 1983, 2.000 Masak Komunikasi Ministries All rights reserved.)

[4] Bratcher, Roberth. Pedoman Penafsiran Alkitab. Jakarta: LAI , 2005

Boland, B.J.. Injil Lukas. Jakarta: BPK gunung Mulia, 1996

[5] Biblesoft's New Exhaustive Strong's Numbers and Concordance with Expanded Greek-Hebrew Dictionary. International Bible Translators, 2006

[6] Budiharto. Metodologi Penelitian Kedokteran.

[7] Chandra, Budiman. Pengantar Statistik Kesehatan. Jakarta: Penerbit buku Kedokteran, 1995

[8] Danim, Sudarwan. Riset Keperawatan. Jakarta: Penerbit Buku kedokteran EGC, 2003

[9] __ Departemen Pendidikan dan Kebudayaan, Kamus Besar Bahasa Indonesia. Jakarta: Balai Pustaka,1990

[10] Eerdmans, William B.. Exegetical Dictionary of the New Testament. Publishing Company, 1990.

[11] Fathoni, Abdurrahmat, M.Si. Metodologi Penelitian \& Teknik Penyusunan

Skripsi. Jakarta: PT Rineka Cipta, 2006. 
[12] Greek-English Lexicon Based on Semantic Domain, United Bible Societies ; New York, 1988

[13] Guthrie,Donald.Pengantar Perjanjian Baru.Surabaya: Momentum, 2008

[14] Harinaldi. Prinsip - Prinsip Statistik untuk teknik dan sains. Jakarta : Erlangga , 2009

[15] Han, Yap Un. Problematika Hamba Tuhan. Manado:Yayasan Daun Family, 2004

[16] Henry, Mattew. Injil Lukas. Surabaya: Momentum, 2009

[17] Hershberger, Michele. Hospitalitas.Jakarta: BPK Gunung Mulia, 2009

[18] Http://merahitam.com/metodepenelitian-jenis-dan-data.html

[19] Husein Umar, Business An Introduction. Jakarta : PT Gramedia Pustaka Utama, 2000 handbook Ilmu \& Aplikasi Pendindikan. Jakarta:PT Imperial Bhakti

Utama, 2007

[21] Jhonston, Philip. Pengantar untuk mengenal Alkitab.Bandung:

Hidup Yayasan Kalam

[22] Joyner, Rick. Kepemimpinan: Kekuatan dari Hidup Yang Kreatif. Jakarta:Nafiri Daniel, 2004

[23] Juanda, J. (2016). Pengaruh Kelas Pendalaman Iman Anak Lebak Arum (Piala)
Terhadap Pertumbuhan Rohani Anak Usia 11-14 Tahun Di Kompleks Perumahan

Lebak Arum Surabaya. Journal Kerusso, $1(1), 51-56$.

[24] Kristemaker, Simon J.. Perumpamaan - perumpamaan Yesus. Malang: SAAT, 2010

[25] Keener, Craig S.Bible Background Commentary New Testament

Published.InterVarsity Press, 1993

[26] Kurniawan, Albert. Belajar Mudah SPSS. Yogyakarta: Media Kom, 2012

[27] Leks, Stefan. Tafsir Injil Lukas. Yogyakarta: Kanasius, 2002

[28] London, H.B Jr, Neil B.Wiseman. Pelayan Allah Yang Berjiwa Besar. Jakarta:

Yayasan Pekabaran Injil “Imanuel”, 1994

[29] Maxwell, John C. Menggembangkan Kepemimpinan Di Dalam Diri Anda.

Jakarta: Binarupa Aksara,1995

[30] Masyhuri dan M.Zainuddin. Metodologi Penelitian Pendekatan Praktiks dan Aplikatif. Bandung: PT. Refika Aditama, 2008

[31] Nisfianoor, Muhammad. Pendekatan Statistika Modern. Jakarta: Salemba Humanika, t.t.

[32] Nursalam. konsep dan penerapan metodologi penelitian ilmu keperawatan.

Jakarta: Salemba Medika, 2008

[33] Pandensolang, Welly. Kristologi Kristen. Jakarta:YAI Press, 2009 
[34] Pasaribu,Marulak.Eksposisi Injil

Sinoptik. Malang:Gandum Mas, 2005

[35] Prasetyo, Widi, et al. "Measuring the Quality of God's Servants According to Acts 6: 3 At the Surabaya City Tabernacle Pentecostal Church." Journal KERUGMA 2.1 (2019): 24-33.

[36] Purwanto, Agus. Panduan Laboratorium Statistik Inferensial, Jakarta: Grasindo,2007.

[37] Pujiati, Suhermin Ari. Penggunaan $R$ dalam Farmasi . Akademik Publisher

[38] Relling, J. dan J.L.Swellengrebel. Injil Lukas. Jakarta: LAI, 2005. Robertson's Word Pictures, the New Testament, Electronic.Broadman

Press, 2006.

[40] Rumiyati, Rumiyati, et al. "Pengaruh Kepemimpinan Hamba Tuhan Dalam Pertumbuhan Kerohanian Jemaat Gereja GPdI 'Zion'Krebet, Tembalang, WlingiBlitar." Journal Kerusso 3.2 (2018): 9-19.

[41] Santoso,David Iman. Teologia Lukas. Malang:Literatur Saat, 2010.

[42] Sarwono, Jonathan. Pintar Menulis Karya Ilmiah. Yogyakarta: CV Andi Offset,

[43] Semma, Mansyur. Negara dan Korupsi. Jakarta: Yayasan Obor Indonesia,2008.
[44] Sugiyono. Metode Penelitian Administrasi. Alfabeta: Bandung, 2007

Soegoto, Eddy Soeryanto. Marketing Research. Bandung: Media: Komputindo, t.t.

[45] Siagian, Dergibson. Metode Statistika. Jakarta: PT Gramedia Pustaka Utama , 2006.

[46] Suprapto,J.Statistik untuk Pemimpin berwawasan Global. Jakarta: Salemba

Empat, 2007.

[47] Setiawan, Conny R.. Metode Penelitian Kualitatif, Jenis, Karakteristik dan Keunggulannya . Jakarta: Grasindo, t.t.

[48] Spiegel, Murray R. Probabilitas dan Statistik. Jakarta: Erlangga, 2009.

[49] Sutanto, Hasan. Interlinier Yunani Perjanjian Baru. Jakarta: LAI, 2006.

[50] Tenney, Merril C. Survei Perjanjian Baru. Malang:Gandum Mas, 2003.

[51] Tuluan, Ola. Introduksi Perjanjian Baru. Jawa Timur:Literatur YPPII, t.t.

[52] Word Studies Vincent dalam Perjanjian Baru. Biblesoft: database elektronik, 1997 
Jurnal Teologi \& Pelayanan ( Kerusso )

E-ISSN: 2714-9587

P-ISSN: 2407-554X

[53] Warren, Rick. The Purpose Driven

Life. Malang:Gandum Mas, 2001

[54] Widianto, K., Permana, S., \& Juanda, J. (2019). The Effect of Church Community Development and Pastoral Services on The Growth of The Congregation of The Bethel Indonesia Church, Family Blessing Surabaya. Journal KERUGMA, 2(2), 1-21.

[55] West, Richard. pengantar teori Komunikasi. Jakarta: Salemba Humanika,2008

[56] Yudhistira. Sosiologi suatu kajian kehidupan masyarakat. Jakarta: Ghalia Indonesia , 2007 